\title{
Promoting The Integrated Community Case Management of Under-Five Pneumonia In Nigeria: A Cost-Benefit Analysis
}

Charles Okafor ( $\nabla$ charles.okafor@griffithuni.edu.au )

Griffith University https://orcid.org/0000-0002-7048-910X

Obinna Ekwunife

Nnamdi Azikiwe University Faculty of Pharmaceutical Sciences

\section{Research}

Keywords: Amoxicillin dispersible tablet, Benefit, Education, Support, Nigeria

Posted Date: July 16th, 2020

DOI: https://doi.org/10.21203/rs.3.rs-42876/v1

License: (c) (1) This work is licensed under a Creative Commons Attribution 4.0 International License.

Read Full License 


\section{Abstract}

\section{Background}

While evidence-based recommendations for the management of under-five pneumonia at the community level were made by the World Health Organisation, the implementation remains poor in Nigeria. Initiatives to promote the integrated community case management (iCCM) of pneumonia through the proprietary and patent medicine vendors (PPMVs) have been poorly utilized possibly due to low financial support and perceived benefit. This study provides cost and benefit estimates and implications of promoting the iCCM through the PPMVs' education and support. The outcome of this study will help inform healthcare decisions in Nigeria.

\section{Methods}

This study was a cost-benefit analysis using simulation-based decision-analytic Markov model. Two approaches were compared, the current scenario which is the use of amoxicillin dispersible tablet (DT) and amoxicillin DT plus promotion. Health outcomes include disability-adjusted life years averted (converted to monetary benefit) and severe pneumonia hospitalisation cost averted. Both the cost and benefit were expressed in 2018 US dollars.

\section{Results}

The incremental benefit-cost ratio of promoting the iCCM was 1.37, while the total net-benefit was $\$ 3.31$ (95\% Cl: \$2.08 - 4.76) million from the whole country perspective, which will offset over three-quarter of the promotion cost. Implementing the promotion exercise at a cost above $\$ 6.82$ million will not be a worthwhile decision.

\section{Conclusion}

Promoting the iCCM for the treatment of pneumonia in children under-five through education and support of the PPMVs holds promises to harness the benefits amoxicillin DT and provide a high return on investment. A nationwide promotion exercise should be considered especially in remote areas of the country.

\section{Background}

The World Health Organisation (WHO) recommends the use of oral amoxicillin dispersible tablet (DT) as the first-line agent in the management of uncomplicated cases of under-five pneumonia at the community level and parenteral penicillin and gentamicin as first-line in severe cases [1], but implementation in Nigeria remains low especially in rural communities.

The Nigerian Ministry of Health in collaboration with the Maternal and Child Survival Program (MCSP), and the WHO has implemented the Saving One Million Lives project [2]. This project aims to support 
community case management of illness such as pneumonia, malaria and diarrhoea as a strategy to improve treatment access and coverage especially for children living in rural areas [3]. The integrated community case management (iCCM) strategy enables assessment, classification, treatment and referral of pneumonia, diarrhoea and malaria cases [4]. The United Nations agencies and other donor agencies have supported the implementation of the iCCM in Nigeria [2]. Following the implementation of the national iCCM guidelines in the year 2013, the occurrence of childhood illness has reduced, and management of pneumonia improved but implementation remains poor [2]. A plausible reason for the poor result was the initial focus of iCCM promotion on community health workers and less focus on the proprietary and patent medicine vendors (PPMVs) who are ubiquitous in the communities. The PPMVs are drug vendors without formal training in pharmacy and are issued a licence by the Pharmacist Council of Nigeria (PCN) to retail non-prescription medications. The iCCM strategy has led to the removal of amoxicillin DT from the prescription-only medicine list to enable the PPMVs to have access to the drug for the treatment of non-severe childhood pneumonia at the community level [5]. In Nigeria, this decision was also supported by the fact that majority of the populace in rural areas visit PPMVs for medical advice, diagnosis, medications and general health management due to their low service cost and accessibility [6,7]. A study in Uganda has also shown that PPMVs are indispensable at the rural communities [8]. The coalition promoting the iCCM foresaw a problem of abuse and increased resistance to amoxicillin DT due to the possibility of irrational dispensing. This foreseen challenge called for the need to educate PPMVs (due to their low medical knowledge) who will sell the amoxicillin DT to most patients. The training of PPMVs involves basic education about signs of pneumonia including danger signs, use of respiratory rate timers, how to dose the drug and when to refer patients in complicated cases to healthcare facilities.

The MCSP in collaboration with the United States Agency for International Development (USAID) made an education outreach in the year 2017 in four local government areas (Idah, Okehi, Izzi and Ohaozara) of two states in Nigeria (Kogi state and Ebonyi state) to test the feasibility of promoting iCCM through the PPPVs [9]. The training held also included education on management of diarrhoea and malaria at the community level and when to refer patients to healthcare facilities [9]. In addition to supporting one of the training in Kogi state, Nemel Pharmaceuticals Limited, an indigenous pharmaceutical company of Nigeria in the year 2018 sponsored the iCCM training through the PCN in few local government areas of Enugu state and the Federal Capital Territory of Nigeria [9]. The outreach reported over $90 \%$ turn out of the expected trainees. Following the successful implementation of the training, the PPMVs national executive committee demanded promotion in other PPMVs locations. However, the promotion was decelerated possibly due to fund limitation and low perceived benefit [9]. This lacuna calls for evidence-based analysis of its benefit to encourage the government and donor agencies buy-in. This problem has informed the need for health economic evaluation of the promotion exercise to assess whether scale-up of education and support of PPMVs in the practice of iCCM for under-five pneumonia management will be beneficial to Nigeria.

This study, therefore, aimed to evaluate the cost and benefit of promoting iCCM for the management of pneumonia for children under five years in Nigeria through education and support of PPMVs. 


\section{Methods}

\section{Study setting and sample size}

The study was carried out using a decision-analytic Markov cohort model and depicted the Nigerian scenario. The population used in the study was an estimated size of 34.6 million Nigerian children under five years. This figure was based on the 2018 population report [10]. This population was used as the starting population in the model (well state) but at risk of having childhood pneumonia.

\section{Study perspective}

The study used retrospective data related to Nigeria to estimate the benefit and cost of promoting iCCM through the PPMVs. The cost was estimated from the payers' perspective (government, donor agencies or third-party payer).

\section{Interventions}

A. Amoxicillin DT: In this scenario (current scenario), amoxicillin DT is given to patients with non-severe pneumonia (moderate pneumonia) where the child has fast breathing pneumonia at a dose of $80 \mathrm{mg} / \mathrm{kg} /$ day in two divided doses for 5 days.

B. Amoxicillin DT plus promotion: In addition to amoxicillin DT for 5 days as in the current scenario above, this scenario (promotion scenario) involves the training of the PPMVs on signs of pneumonia including danger signs, use of respiratory rate timers, how to dose the drug and when to refer patients in complicated cases to healthcare facilities. It also includes the free distribution of one respiratory rate timer to each PPMV shop.

\section{Choice of model and assumptions}

We used a simulation-based decision-analytic Markov model in our analysis with a yearly cycle for 5 years. The states in the model were: well state, moderate (clinical) pneumonia, severe pneumonia and death $[11,12]$. The starting age in the model was under-one year. The model was developed using Nigerian-specific data. The transition probabilities of moving to moderate and severe states were estimated from the national incidence rates from a global systematic review $[1,11]$. Yearly incidence rates were converted to yearly probabilities using the formula, $P=1$ - where $P=$ probability, $r=$ rate and $t=$ time (year). The mortality rate from all-cause of disease and from pneumonia were obtained from the 2017 Institute of Health Metrics and Evaluation report for Nigeria [13]. In the model, children will start from the well state and with each cycle, they may remain well, move to moderate or severe pneumonia or may die as shown in Figure 1.

Figure 1: Model figure

Based on recent education programs to PPMVs conducted by the MCSP, the USAID and the PCN described earlier and elsewhere [9], we estimated that one health educator will train 10 PPMVs per day (in 
two sessions); 4 training sessions ( 2 days) will be held per week per health educator; 16 training sessions will be held per month per health educator and 176 training sessions will be held per annum (11 months) per health educator. The experience from the recent outreach revealed that at least a day-spacing is necessary for trainers to prepare for and travel to the next training venue. We assumed that for each PPMV shop, one representative will be trained. The number of PPMV shops was obtained from a recent survey in Nigeria as 24.58 per 100,000 population [14]. Thus, 55 health educators will be required based on this estimate. We included two extra educators in case of unforeseen shortfall of educators which brings the total to 57 educators. Based on Nigeria's 6 geopolitical zones, 8 educators were assigned to each of four geopolitical zones (north-central; northeast; south-east; and south-south). A total of 12 and 11 educators were assigned to north-west and south-west zone respectively due to their relatively high population with north-west having the highest in Nigeria. One educator will be stationed in the northern region in case of any surge or demand while the other in the southern region. Two vehicles; two computers and two electronic projectors will be allocated to each geopolitical zone. The outreach in 2018 showed that at least five educators were needed for each training to carter for the number of the trainees.

The PPMV shops and community pharmacies are the major providers of health service at the community level for non-severe health conditions in Nigeria. The survey by the MCSP and the USAID showed that care-seeking at PPMVs shops for fever, diarrhoea, cough or pneumonia was $43 \%$ in Nigeria and was used in this study [9]. Overall care-seeking at health facilities was found to be about $40 \%$ [2,9]. Details of the assumptions are shown in Table 1 and Additional file 1.

Table 1: Input data and assumptions in the model

\section{Time horizon and discount rate}

The model simulated cost and outcome within the period of 0 to 5 years for a population of 34.6 million at risk of having pneumonia. Cost and benefit (health outcome) were discounted at a rate of $5 \%$ [17].

\section{The measure of effectiveness (relative risk ratio)}

The effectiveness of promoting iCCM for pneumonia was modelled as relative risk. The relative risk ratio was obtained from a recent study in Uganda that compared the effect of promotion (through PPMVs education and support with a diagnostic kit and amoxicillin DT) to no promotion [8]. Details of parameters inputs and distribution are shown in Table 2.

\section{Health outcome}

The primary benefit of the promotion was measured in terms of disability-adjusted life years (DALY) averted. The DALY calculation was based on 2017 global burden of disease study and we used recently updated disability weights for moderate and severe pneumonia [18]. The DALY was calculated as the sum of the years of life lived with disability (YLD) from morbidity and the years of life lost (YLL) from mortality. The DALYs were calculated for each cycle and accumulated over the time horizon of five years and averaged to obtain the mean DALY per patient. In calculating the monetary value of a DALY, we used 
the Harvard-led guideline for conducting a benefit-cost analysis project [19]. The valuation was based on "value of statistical life year" (VSLY) with one DALY averted valued at 1.3 times the GNI per capita of a country in sub-Saharan Africa. The secondary outcome was measured as the cost of hospitalisation due to severe pneumonia averted.

Table 2: Parameters and distribution in the Markov model

\section{Determination of cost}

The cost was estimated from the payers' perspective. The cost component for the current scenario (amoxicillin DT) includes the cost of amoxicillin DT ( $1 * 10$ pack) for children $\leq 1$ year $(2-12$ months) or $2 \star 10$ pack (for children $\geq 1 \leq 5$ years) which are the recommended pack sizes [22]. In the promotion scenario, the cost components include amoxicillin DT as in the current scenario above plus the cost of the promotion. The administrative cost components for promotion were obtained from WHO-CHOICE [15] for AFRO D region. The components include a program director, a program coordinator, health educators, an administrative officer, a data entry clerk, a finance officer, vehicles, vehicle drivers, a logistic officer, office, and an external consultant. The cost values were discounted to 2018 USD. The costs were converted using the price level ratio of Naira to US dollar. The cost of other components like electrical utility was obtained from the Nigerian electricity regulatory commission rate [16]. The cost of telephone calls, electronic projectors, hotel accommodation, travel allowance and computers, were estimated based on the recent education outreach conducted in 2018 in Nigeria and from surveys. The costs used in the model were annual costs since the model runs in a yearly cycle. The cost of vehicles was annualised based on useful life years of 8 years [15] while 1year useful year was used for the electronics. The cost of promotion was distributed across the under-five non-severe pneumonia incidence and based on the caregivers' PPMV care-seeking (43\%). All costs were expressed in 2018 US dollars. Gamma distribution was used to capture the uncertainty inherent in the cost parameters. Details of the costs are shown in Table 2 and Additional file 1.

\section{Data analysis}

We estimated the cost per treatment course. Based on the report of 0.29 episodes of pneumonia per child year in developing countries [24], we then estimated the cost per annum which was used in the model. The cost data, transition probabilities, relative risk and utilities were made probabilistic using the appropriate distributions as shown in Table 2. The DALY was calculated by combining the YLD and YLL for each cycle year. YLD = number of cases duration till remission or death disability weight $[25,26]$. YLL = number of deaths due to pneumonia life expectancy at the age of death [26]. The standard life expectancy of < 1 year (54.7) and $1-4$ years of (57.9) was obtained from the Nigerian life table [27]. The DALYs across each cycle was summed and averaged to obtain the standard DALYs which was used in the probabilistic sensitivity analysis (PSA). The DALYs averted was calculated as the difference between the DALYs lost in the current scenario (amoxicillin DT) and the promotion scenario (amoxicillin DT plus promotion). Half cycle correction using the life table method was employed in the model [28]. The PSA was used to assess simultaneous uncertainty in the variables. This approach is well suited to express 
overall parameters uncertainty [29]. To assess how simultaneous change of several variables affects the cost and benefit, a Monte-Carlo simulation (1000 iterations) was performed (a type of multivariate sensitivity analysis). This technique runs many simulations by repeatedly drawing samples from probability distributions of input variables. Data were analysed using Microsoft 365 Excel.

\section{Results}

\section{Costs and benefits}

From the analysis, the mean cost per patient following the current scenario (amoxicillin DT) was $\$ 0.49$ (95\% Cl: $\$ 0.48$ - 0.50) while the promotion scenario (amoxicillin DT plus promotion) was $\$ 8.77$ (95\% Cl: $\$ 8.58-8.96)$. The incremental cost per patient treatment for scaling up promotion was $\$ 8.29$ (95\% Cl: $\$ 8.10-8.50)$. The estimated cost of promoting the iCCM through the PPMVs was $\$ 3.41$ (95\% Cl: $\$ 3.40-$ 3.42) million. The DALY averted per patient due to the promotion of iCCM for the management of pneumonia was 0.004 , which translates to a benefit of $\$ 11.31$ (95\% Cl: $\$ 10.27-12.35)$ per patient, and a net benefit of $\$ 2.54$ (95\% Cl: $\$ 1.50-3.58)$ per patient, and a total benefit of $\$ 4.41$ (95\% Cl: $\$ 3.99-4.80)$ million for the country. With a 2018 gross national income per capita of $\$ 1960$, the benefit-cost ratio (BCR) of the promotion was 1.29, while the incremental BCR was 1.37 per patient. The result showed that the difference in the number of cases of severe pneumonia between the current scenario and the promotion scenario was 146,837 cases (in favour of the promotion scenario). The number of severe pneumonia hospitalisations averted based on $40 \%$ care-seeking at health facilities was 58,735 cases. Following the $\mathrm{WHO}$ guideline for the treatment of severe pneumonia and the paediatrician association of Nigeria guideline [30], the cost of hospitalisation for severe pneumonia is $\$ 39.35(25.39-51.20)$ per case, which will yield a benefit of $\$ 2.31$ (95\% Cl: $\$ 1.49-3.38)$ million from the cost of severe hospitalisation averted. These translate to a total benefit $\$ 6.72(95 \% \mathrm{Cl}: 5.48-8.18)$ million and a net benefit of $\$ 3.31$ (95\% Cl: $\$ 2.08-4.76$ ) million, which will offset $97 \%$ of the cost of promotion. The results are summarised in Table 3.

To test the effect of uncertainty of our assumptions on the outcome, we used a conservative approach of sensitivity analysis by increasing the cost of promotion by $25 \%, 50 \%$ and $100 \%$ ( 2 times increase). The sensitivity test showed that a $25 \%$ increase in the cost of the promotion will still be beneficial (BCR $=$ 1.10). Worse-case scenarios of $50 \%$ and a $100 \%$ increase in the cost were still beneficial, with BCR of 0.93 and 0.74 , but total net-benefit of $\$ 1.75$ and $\$ 0.4$ million respectively. However, a $125 \%$ (2.25 times) increase in the investment yielded a net-loss of $\$ 0.46$ million.

Table 3: Per patient cost, benefit and benefit-cost ratio of the promotion

\section{Discussion}

While evidence-based recommendations for the management of under-five pneumonia were made by the WHO, the implementation remains poor in Nigeria. Initiatives to promote the iCCM through the PPMVs 
has been poorly utilized possibly due to low financial support and perceived benefit. No study has quantified its cost and benefit in Nigeria, a region with high pneumonia incidence and mortality. This study provided costs and benefits estimates and implications that will guide decision making in the country. The study showed that iCCM promotion through the PPMVs using the method described will be beneficial to Nigeria. Our analysis shows that $97 \%$ of the cost of the promotion will be offset if the scaleup of the promotion is initiated.

The analysis was based on a specific price of amoxicillin DT. There is a need for price regulation of the drug. The Nigerian government or donors can provide customized packs of amoxicillin DT to PPMVs and affix an indelible price tag on the mono-packs of the drug (with the PPMVs mark-up included). For instance, a pack of $1 * 10$ tablets supplied at $\$ 0.23$ will have an indelible price tag of $\$ 0.28$ (20\% mark-up) on the packs so that the PPMVs retailers sell at a fixed price. The caretakers of patients who come to buy the drug, on seeing the price tag already know what to pay. This additional support will further guarantee the success of iCCM promotion through PPMVs. This will impel the PPMVs as they will be motivated to make more sales while implementing the service. On the other hand, the Nigerian GDP will grow as more lives are saved.

The PPMV education outreach conducted in 2017 and 2018 incorporated education for malaria and diarrhoea management also. Thus, no additional resources need to be invested to provide education for malaria and diarrhoea management to the PPMVs. This implies that the actual cost for promoting underfive pneumonia management can become approximately one-third of the estimated amount in this study, which will lead to cost-saving.

This study has some limitations. The assumptions in estimating the cost of promoting iCCM through PPMVs might vary should implementation be done. The study estimates and assumptions were based on the recent outreach. The sensitivity analysis showed that at a high cost of promotion up to $100 \%$ increase, the benefit will outweigh the cost. However, implementation cost above 2 times the estimated cost in this study will not be beneficial to Nigeria. Thus, at a cost of promotion above $\$ 6.82$ million, the cost will outweigh the benefit and as such, the promotion will not be a worthwhile decision. Secondly, our estimate did not capture alternate treatment cost in case of the first-line failure. It also failed to capture the treatment approach for human immunodeficiency virus (HIV) patients with pneumonia or patients at risk of HIV $[1,30]$. Thirdly, we did not include the treatment of chest indrawing pneumonia with amoxicillin DT since it is not covered in the iCCM tool. We assumed that treatment failures at iCCM level will be referred to health facilities and, in this case, amoxicillin DT would likely not be repeated but parenteral medications.

Nigeria is the giant of Africa, but the country has lost so many human resources and funds due to lack of information and right implementation practice. Most useful healthcare implementations are poorly sustained. The high mortality rate of children under-five in the country calls for a pragmatic approach to ameliorate the problem. Being the "future of tomorrow", protecting the Nigerian children under-five should 
not be negotiated, otherwise, the frontier of 'gigantism and dwarfism of Africa' for Nigeria will become narrower.

\section{Conclusion}

The use of amoxicillin DT is very beneficial to Nigeria in cases of non-severe pneumonia, but its benefits have been poorly harnessed. Promotion of iCCM for the treatment of pneumonia in children under-five through education and support of the PPMVs holds promises to harness these benefits and additional benefits to the economy, providing a high return on investment. A nationwide promotion exercise should be considered especially in remote areas of the country.

\section{Abbreviations}

DT

Dispersible tablets

MCSP

Maternal and child survival program

iCCM

Integrated community case management

PPMV

Proprietary and patent medicine vendors

PCN

Pharmacists council of Nigeria

USAID

United States agency for international development

YLD

Years lived with disability

YLL

Years of life lost

DALY

Disability-adjusted life years

\section{Declarations}

\section{Ethical approval and consent to participate}

Not applicable

\section{Consent for publication}

Not applicable 
Availability of data and materials

Data used in the study are provided in supplementary file

\section{Competing interest}

The authors declare that they have no competing interests

\section{Funding}

The authors received no funding for this research

\section{Authors' contributions}

$\mathrm{CO}$ was responsible for conceptualization and data curation. $\mathrm{CO}$ and $\mathrm{OE}$ developed the study design. $\mathrm{CO}$ performed the data analyses. $\mathrm{CO}$ wrote the first draft. OE reviewed the manuscript. All authors reviewed the final manuscript.

\section{Acknowledgement}

Not applicable

\section{References}

1. WHO. Revised WHO Classification and Treatment of Childhood Pneumonia at Health Facilities: Evidence Summaries. World Health Organization. 2014. 26 p.

2. Adebayo S, Ishola G, Adeyemi A. Integrated Community Case Management of Childhood Illnesses: Assessment of Nigeria's Program. 2017;(September).

3. Marsh D, Gilroy K, Weerdt R, Qazi S. Community case management of pneumonia: at a tipping point ? [Internet]. Vol. 86, Bulletin of the World Health Organization. 2008. Available from: http://www.who.int/bulletin/volumes/86/5/07-048462.pdf.

4. USAID/MCHIP USAID/MCHIP. INTEGRATED COMMUNITY CASE MANAGEMENT OF CHILDHOOD. ILLNESS:Documentation of Best Practices and Bottlenecks to Program Implementation in the Democratic Republic of Congo (DRC). 2012;(January). Available from: https://www.mchip.net/sites/default/files/mchipfiles/DRCLongEnglish.pdf.

5. UNICEF. Integrated Community Case Management (iCCM). and the role of pneumonia diagnostic tools Theresa Diaz MD MPH Senior Health Advisor Health Section [Internet]. 2014. Available from: https://www.malariaconsortium.org/userfiles/file/ASTMH UNICEF iCCM and pneumonia diagnostic tools.pdf.

6. National Population Commission|ICF International. Nigeria: demographic and health survey [Internet]. 2013 [cited 2020 Jan 25]. Available from: 
https://dhsprogram.com/pubs/pdf/FR293/FR293.pdf.

7. Ajayi IO, Falade CO, Adeniyi JD, Bolaji MO. The Role of Patent Medicine Sellers in Home Management of Childhood Malaria: A Situational Analysis of Experience in Rural Nigeria. Int Q Community Health Educ. 2002;21(3):271-81.

8. Awor P, Wamani H, Tylleskar T, Jagoe G, Peterson S. Increased access to care and appropriateness of treatment at private sector drug shops with integrated management of malaria, pneumonia and diarrhoea: A quasi-experimental study in Uganda. PLoS One. 2014;9(12):1-15.

9. USAID/MCSP. Findings from the Enhancing Quality iCCM through Proprietary and Patent Medical Vendors (PPMV) and Partnerships (EQuiPP) Approach [Internet]. 2019 [cited 2020 Mar 10]. Available from: https://www.childhealthtaskforce.org/sites/default/files/2019-08/MCSP EQuiPP \%28PSE Subgroup Meeting\%29_07.30.2019.pdf.

10. World Population Data Sheet. World Population Datasheet: With a Special Focus on Changing Age Structures. Popul Ref Bur Bull [Internet]. 2018;20. Available from: https://www.prb.org/wpcontent/uploads/2018/08/2018_WPDS.pdf.

11. $10.1016 / S 2214-109 X(18) 30408-X$

Mcallister DA, Liu L, Shi T, Chu Y, Reed C, Burrows J, et al. Global, regional, and national estimates of pneumonia morbidity and mortality in children younger than 5 years between 2000 and 2015 : a systematic analysis. Lancet Glob Heal [Internet]. 2019;7(1):e47-57. Available from: http://dx.doi.org/10.1016/S2214-109X(18)30408-X.

12. Pitt $C$, Roberts B, Checchi F. Treating childhood pneumonia in hard-to-reach areas: A model-based comparison of mobile clinics and community-based care. BMC Health Serv Res [Internet]. 2012;12(1):9. Available from: http://www.biomedcentral.com/1472-6963/12/9.

13. Institute for Health Metrics and Evaluation. Global Burden of Disease Study 2017 (GBD 2017) Results. Seattle, United States: [Internet]. 2018. Available from: http://ghdx.healthdata.org/gbdresults-tool.

14. Liu J, Beyeler N, Prach L, Sieverding M, Isiguzo C, Nwokolo E, et al. The Landscape of Patent and Proprietary Medicine Vendors in 16 States of Nigeria: Society for Family Health. 2015.

15. WHO-CHOICE. Price of Local (Non-traded) Goods: AFRO D [Internet]. 2005. Available from: https://www.who.int/choice/costs/prog_costs/en/.

16. Nigerian Electricity Regulatory Commision. EKO DISCO Tariff [Internet]. 2018 [cited 2020 Mar 10]. Available from: https://nerc.gov.ng/nercdocs/tariffs/eko-tariff.pdf.

17. Haacker M, Hallett TB, Atun R. On discount rates for economic evaluations in global health. Health Policy Plan. 2020;35(1):107-14.

18. IHME. Global Burden of Disease Study 2017. (GBD 2017) Disability Weights [Internet]. 2017. Available from: http://ghdx.healthdata.org/record/ihme-data/gbd-2017-disability-weights.

19. Robinson LA, Hammitt JK, O'Keeffe L. Valuing Mortality Risk Reductions in Global Benefit-Cost Analysis. J Benefit-Cost Anal. 2019;10:15-50. 
20. Dang TT, Eurich DT, Weir DL, Marrie TJ, Majumdar SR. Rates and risk factors for recurrent pneumonia in patients hospitalized with community-acquired pneumonia: Population-based prospective cohort study with 5 years of follow-up. Clin Infect Dis. 2014;59(1):74-80.

21. Unicef. Amoxicillin Dispersible Tablets (DT): Product Profile, Availability and Guidance. 2013;(July):7.

22. UNICEF Supply Division. Amoxicillin Dispersible Tablets: Market and Supply Update. 2018;(May):19. Available from: https://www.unicef.org/.

23. UNICEF. Acute Respiratory Infection Diagnostic Aid (ARIDA) Project. 2019;(November).

24. Rudan I, Boschi-Pinto C, Biloglav Z, Mulholland K, Campbell H. Epidemiology and etiology of childhood pneumonia. Bull World Health Organ. 2008;86(5):408-16.

25. WHO. Disability-Adjusted Life Year (DALY). Quantifying the Burden of Disease from mortality and morbidity. [Internet]. 2012 [cited 2015 Aug 1]. Available from: http://www.who.int/healthinfo/global_burden_disease/metrics_daly/en/.

26. WHO. Global Burden of Disease Concept [Internet]. 2004 [cited 2015 Aug 1]. Available from: http://www.who.int/quantifying_ehimpacts/publications/en/9241546204chap3.pdf.

27. WHO. The Nigerian Life Table [Internet]. 2013 [cited 2015 Jun 1]. Available from: http://apps.who.int/gho/data/view.main.61200?lang=en.

28. Barendregt JJ. The life table method of half cycle correction: Getting it right. Med Decis Mak. 2014;34(3):283-5.

29. Briggs A, Claxton K, Sculpher M. Decision modeling for health economic evaluation. New York: Oxford University Press Inc; 2006.

30. Olowu A, Elusiyan J, Esangbedo D, Ekure E, Esezobor C, Falade A, et al. Management of community acquired pneumonia (CAP) in children: Clinical practice guidelines by the Paediatrics Association of Nigeria (. PAN ). 2015;42(4):283-92.

\section{Tables}

Table 1: Input data and assumptions in the model 


\section{PPMVs and Educators}

\begin{tabular}{llll} 
Number of PPMV shops per 100,000 population & 24.58 & $( \pm 10 \%)$ & {$[14]$} \\
\hline Estimated number of PPMV shops in Nigeria & 48146 & $( \pm 10 \%)$ & {$[14]$} \\
\hline The ratio of PPMVs to health educators & $10: 1$ & N/A & Year 2018 outreach \\
\hline Number of training per week per educator & 4 & N/A & Year 2018 outreach \\
\hline Training per educator per annum & 176 & $( \pm 10 \%)$ & Year 2018 outreach \\
\hline Health educators needed (2 additional) & 57 & $( \pm 10 \%)$ & Year 2018 outreach \\
\hline The average number of trainees per meeting & 80 & $(50-100)$ & Year 2018 outreach \\
\hline Number of training auditoriums & 602 & $( \pm 10 \%)$ & Year 2018 outreach \\
\hline Training refreshments & 53162 & $( \pm 10 \%)$ & Year 2018 outreach \\
\hline Care-seeking at PPMV shops & $43 \%$ & $( \pm 10 \%)$ & {$[9]$} \\
\hline Overall care-seeking at health facilities & $40 \%$ & $( \pm 10 \%)$ & {$[2,9]$} \\
\hline Number of respiratory rate timers & 48146 & $( \pm 10 \%)$ &
\end{tabular}

\section{Administrative Requirements}

\begin{tabular}{|llll|}
\hline Program director & 1 & N/A & {$[15]$} \\
\hline Program coordinator & 1 & N/A & {$[15]$} \\
\hline Administrative officer & 1 & N/A & {$[15]$} \\
\hline Office and space (1000 meters square) & 1 & N/A & {$[15]$} \\
\hline Data entry clerk & 1 & N/A & {$[15]$} \\
\hline Finance officer & 1 & N/A & {$[15]$} \\
\hline Health educators/Trainers & 57 & $( \pm 10 \%)$ & {$[15]$} \\
\hline External consultant (12 consultations) & 1 & N/A & {$[15]$} \\
\hline Logistics/social worker & 1 & N/A & {$[15]$} \\
\hline Transportation drivers & 14 & N/A & {$[15]$} \\
\hline Vehicles & 14 & N/A & {$[15]$} \\
\hline Useful years of each vehicle & 8 & N/A & {$[15]$} \\
\hline
\end{tabular}




\begin{tabular}{|llll|} 
Electronic projectors for training & 13 & N/A & Year 2018 outreach \\
\hline Computers and Laptops & 16 & $( \pm 10 \%)$ & Year 2018 outreach \\
\hline Useful years of computers and projectors & 1 & N/A & - \\
\hline Transport allowance (frequency) & 602 & $( \pm 10 \%)$ & Year 2018 outreach \\
\hline Electricity utility (KWH) & 12000 & $( \pm 10 \%)$ & {$[16]$} \\
\hline Telephone utility (closed user group) & 70 & $( \pm 10 \%)$ & Local tariff \\
\hline Number of hotel accommodations & 5016 & $( \pm 10 \%)$ & Year 2018 outreach \\
\hline
\end{tabular}

PPMV: Proprietary and patent medicine vendors; KWH: Kilowatts hour

Table 2: Parameters and distribution in the Markov model 


\section{Variable}

Mean

Distribution $(95 \%$

Cl)

\section{Transition Probabilities}

Well to moderate pneumonia

Moderate pneumonia to severe pneumonia

Recurrent moderate pneumonia

Recurrent severe pneumonia

Remaining well

$[1,11,20]$, Model

All-cause mortality

Pneumonia to death

$[1,11,20]$

$[1,11,20]$

$(0.288-0.726)$
0.2607

Beta $(0.1479-$

$0.4161)$

0.0469

Beta $(0.0178-$

0.1068 )

0.0235

Beta $(0.0133-$

0.0375 )

0.0027

Beta $(0.0010-$ 0.0061 )

0.6392

Beta $(0.4004$ -

$0.7981)$

0.0226

Beta $(0.0186$ 0.0275)

0.0044

Beta $(0.0033$ -

$0.0057)$

[13]

Log-normal

$[1,11]$

$[1,11]$

0.507
[13]

[8]

\section{Relative risk of promotion}

Costs

Amoxicillin DT ( $1 * 10$ tablets $) \dagger$

0.28

Gamma (0.21 0.39)

Amoxicillin DT (2*10 tablets)

0.45

Gamma (0.33 0.68)

Program director

23476.57

$\mathrm{N} / \mathrm{A}( \pm 25 \%)$

[15]

Program coordinator

15639.67

$\mathrm{N} / \mathrm{A}( \pm 25 \%)$

[15]

Administration officer

9659.50

$\mathrm{N} / \mathrm{A}( \pm 25 \%)$

[15]

Office and space (1000 meters square)

12065.61

$\mathrm{N} / \mathrm{A}( \pm 25 \%)$

[15]

Data entry clerk

7316.43

$\mathrm{N} / \mathrm{A}( \pm 25 \%)$

[15]

Finance officer

7316.43

$\mathrm{N} / \mathrm{A}( \pm 25 \%)$

[15]

Health educators/Trainers

550591.20

N/A $( \pm 25 \%)$

[15]

External consultant

711.56

N/A ( $\pm 25 \%)$

[15]

Logistics/social worker

9659.50

N/A ( $\pm 25 \%)$

[15]

Transportation drivers

39276.29

N/A ( $\pm 25 \%)$

[15] 


\begin{tabular}{|c|c|c|c|}
\hline Vehicles and maintenance (annualized) & 80892.27 & $\mathrm{~N} / \mathrm{A}( \pm 25 \%)$ & [15] \\
\hline Electronic projectors for training & 2286.98 & $\mathrm{~N} / \mathrm{A}( \pm 25 \%)$ & $\begin{array}{l}\text { Year } 2018 \\
\text { survey }\end{array}$ \\
\hline Computers and Laptops & 6272.87 & $\mathrm{~N} / \mathrm{A}( \pm 25 \%)$ & $\begin{array}{l}\text { Year } 2018 \\
\text { survey }\end{array}$ \\
\hline Transport allowance & 45917.07 & $\mathrm{~N} / \mathrm{A}( \pm 25 \%)$ & [15] \\
\hline Electricity utility (KWH) @ \$0.066/kwh & 792.00 & $\mathrm{~N} / \mathrm{A}( \pm 25 \%)$ & [16] \\
\hline Telephone utility (closed user group) & 2744.38 & $\mathrm{~N} / \mathrm{A}( \pm 25 \%)$ & Local tariff \\
\hline Hotel accommodation & 255135.10 & $\mathrm{~N} / \mathrm{A}( \pm 25 \%)$ & $\begin{array}{l}\text { Year } 2018 \\
\text { survey }\end{array}$ \\
\hline Respiratory diagnostic timer & 2118424.00 & $\mathrm{~N} / \mathrm{A}( \pm 25 \%)$ & [23] \\
\hline Miscellaneous & 12000 & $\mathrm{~N} / \mathrm{A}( \pm 25 \%)$ & - \\
\hline Cost of promotion per episode child year & 0.72 & $\begin{array}{l}\text { Gamma }(0.52- \\
1.21)\end{array}$ & Model \\
\hline Number of pneumonia episodes per child year & 0.29 & N/A & [24] \\
\hline \multicolumn{4}{|l|}{ Disability weights } \\
\hline Moderate (clinical) pneumonia & 0.051 & $\begin{array}{l}\text { Beta }(0.032- \\
0.074)\end{array}$ & [18] \\
\hline Severe pneumonia & 0.133 & $\begin{array}{l}\text { Beta (0.088 - } \\
0.190)\end{array}$ & [18] \\
\hline \multicolumn{4}{|l|}{ Discount rate } \\
\hline Cost & $5 \%$ & $\begin{array}{l}\text { N/A (min 0\%, } \max \\
10 \%)\end{array}$ & [17] \\
\hline Utility & $5 \%$ & $\begin{array}{l}\text { N/A (min 0\%, } \max \\
10 \%)\end{array}$ & [17] \\
\hline
\end{tabular}

t: Cost for $2 * 10$ tablets pack is 1.59 times the cost of 1*10 tablets; DT: Dispersible tablet; KWH: Kilowatts hours

Table 3: Per patient cost, benefit and benefit-cost ratio of the promotion 


\begin{tabular}{|lll|}
\hline & Amoxicillin DT & Amoxicillin DT + Promotion \\
\hline Mean cost $(\$)$ & $0.49(0.48-0.50)$ & $8.77(8.58-8.96)$ \\
\hline DALY averted & - & 0.004 \\
\hline Mean benefit $(\$)$ & - & $11.31(10.27-12.35)$ \\
\hline Net benefit $(\$)$ & - & $2.54(1.50-3.58)$ \\
\hline Incremental cost & - & $8.29(8.10-8.50)$ \\
\hline Incremental benefit-cost ratio & - & 1.37 \\
\hline
\end{tabular}

2018 GNI per capita = \$1960; Benefit/DALY averted = \$2548; DT: dispersible tablet; DALY: disabilityadjusted life years; GNI: gross national income

\section{Figures}

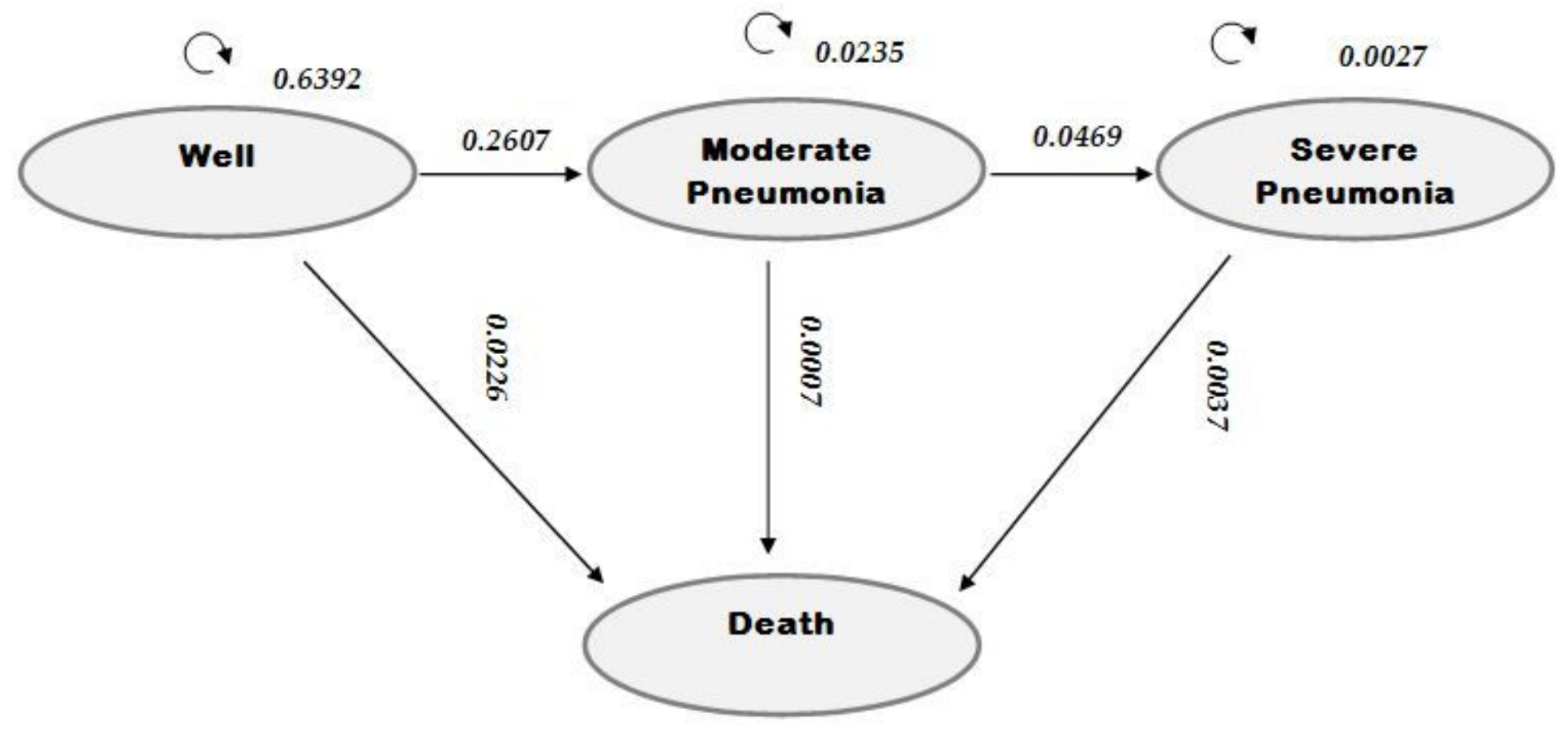

Figure 1

Model figure

\section{Supplementary Files}

This is a list of supplementary files associated with this preprint. Click to download. 
- SupplmentaryfileCERA.xIsm

Page 18/18 